\title{
José María Vigil y la recuperación del pasado colonial en la primera historia de la literatura mexicana
}

\author{
Mónica Quijano Velasco
}

\begin{abstract}
Resumen: En este artículo se reflexiona sobre el proyecto de José María Vigil de escribir una historia de la literatura nacional capaz de integrar — como pasado-, tanto la época prehispánica como el periodo novohispano. Esta articulación no puede considerarse fuera de sus propuestas sobre la necesidad de conformar una historia nacional unificadora. Se complementa esta reflexión con la recuperación que el intelectual jalisciense hace de la figura de sor Juana Inés de la Cruz (como ejemplo del valor de la producción literaria en la época colonial), pues es con Vigil que realmente comienza la revaloración de la obra de la monja novohispana y, por lo tanto, de la época en la cual vivió.
\end{abstract}

АвSTRACT: This article reflects on Jose María Vigil's project of writing a history of Mexican literature in which both the Prehispanic and the Colonial epochs could be integrated. The reflection is complemented with the analysis of the way in which Vigil updates the figure of sor Juana Inés de la Cruz (as an example of the value of the literary production in the colonial period), since it was with Vigil when the revaluation of sor Juana's work — and her era - truly began.

Palabras Clave: José María Vigil, historia de la literatura mexicana, sor Juana Inés de la Cruz.

KeYwords: José María Vigil, history of Mexican Literarure, sor Juana Inés de la Cruz.

FECHA DE RECEPCIÓN: 8 de mayo de 2014 FeCha DE ACEPTACión: 21 de octubre de 2014 



\title{
José María Vigil y la recuperación del pasado colonial en la primera historia de la literatura mexicana
}

\author{
Mónica Quijano Velasco \\ Facultad de Filosofía y Letras, UNAM \\ moquijano@gmail.com
}

El establecimiento de una 'periodización' de la historia de la literatura mexicana a partir de cuatro etapas — la prehispánica, la novohispana, el siglo XIX y la contemporánea- pareciera algo dado de manera natural: en ella se integran las producciones líricas y los mitos de los pueblos precolombinos; los autos sacramentales, sermones, poemas y obras dramáticas del periodo colonial; la Arcadia, el Romanticismo, la novela histórica y el Modernismo decimonónicos; así como el Ateneo, las vanguardias, la novela de la revolución, el grupo de los Contemporáneos $\mathrm{y}$ los narradores, poetas, dramaturgos y ensayistas del siglo $\mathrm{xx}$ (y lo que va del xxI). Todos ellos conforman una unidad que denominamos literatura nacional, la cual ha integrado una serie de autores y textos heterogéneos, en torno a la idea de una literatura común que, entre otras cosas, nos ayuda a definirnos como mexicanos.

Sin embargo, esta visión, interiorizada y transmitida durante el siglo xx a través de la educación, los libros y los manuales escolares, no es tan natural como podría parecer: es, más bien, una construcción historiográfica elaborada durante el siglo XIx. Esto implica que la integración del pasado prehispánico y novohispano a la idea de una literatura mexicana fue el resultado de una transformación, ocurrida a partir de la segunda mitad del siglo XIX, en la cual las elites intelectuales pudieron distanciarse de un pasado conflictivo - como era el colonial - para integrarlo en la idea de una historia común. Las siguientes páginas abordarán, por lo tanto, las reflexiones elaboradas por José María Vigil (1829-1909) sobre su manera de integrar el pasado novohispano en la historia literaria mexicana. Trabajar con esta incorporación del pasado colonial en la obra del intelectual jalisciense nos lleva a una segunda cuestión, no menos importante: la restitución que Vigil realiza de gran parte de la obra de sor Juana Inés de la 
Cruz $^{1}$ frente a una lectura, por lo general negativa, que fue una constante durante el siglo xix. ${ }^{2}$

Ahora bien, el interés de Vigil por la historia nacional está fuertemente vinculado con sus labores magisteriales ${ }^{3}$ y su trabajo como director de la Biblioteca Nacional. ${ }^{4}$ Estas labores orientaron sus reflexiones sobre la historia hacia un enfoque pedagógico, en donde se destaca la importancia del estudio y enseñanza de la "historia patria" en general, así como sobre la historia de la literatura en particular. No es posible por lo tanto entender su proyecto para una historiografía literaria mexicana si no la situamos dentro de su propuesta pedagógica sobre la necesidad de conocer la "historia nacional".

Así, en un ensayo de 1878 titulado "Necesidad y conveniencia de estudiar la historia patria", considera fundamental el estudio del pasado mexicano, tanto del periodo prehispánico como del colonial, ya que, según su punto de vista, los dos obstáculos para el establecimiento de la

${ }^{1}$ Desarrollé una primera versión de las reflexiones sobre la recuperación positiva elaborada por José María Vigil de la obra de la monja novohispana en "Sor Juana Inés de la Cruz y el siglo xIX mexicano: tensiones y encuentros", en Humanismo Novohispano, independencia y liberalismo: continuidad y ruptura en la formación de la nación mexicana. Ambrosio Velasco (coord.), unam / Plaza y Valdés, 2009: 315-331. Para las reflexiones que Vigil hace sobre sor Juana retomo lo desarrollado en este artículo.

${ }^{2}$ Cuando pensamos en la relación que los escritores e intelectuales mexicanos del siglo XIX establecieron con la figura de sor Juana lo primero que nos viene a la mente es pensar que se trató de una "época negra", que no supo apreciar las grandes virtudes literarias de la monja novohispana. Esta acepción se debe, entre otros juicios, a la ya famosa frase de Ignacio Manuel Altamirano, repetida ad infinitud, donde recomienda dejar a sor Juana "quietecita en el fondo del sepulcro y entre el pergamino de sus libros, sin estudiarla más que para admirar de paso la rareza de sus talentos y para lamentar que hubiera nacido en los tiempos del culteranismo, de la Inquisición y de la teología escolástica" ("Carta a una poetisa" citado por Francisco de la Maza 1980: 393). Sin embargo, como hace ver Jorge Ruedas de la Serna, es necesario realizar un estudio más preciso, tratando de situar los comentarios sobre sor Juana en su contexto de producción específico (Ruedas 1998: 213-224).

${ }^{3}$ La carrera magisterial de Vigil inicia en 1855, cuando imparte el curso de latinidad y filosofía en el Liceo de Varones del estado de Jalisco (Navarro Sánchez: X). Asimismo, ocupó la cátedra de lógica en la Escuela Nacional Preparatoria entre 1877 y 1892 . Su participación en la polémica sobre la enseñanza de la lógica en la ENP durante la década de 1880 es fundamental para entender la historia de la enseñanza de la filosofía en México. Para un panorama sobre esta polémica cfr. Illades 2008 y Estrella 2010.

${ }^{4}$ Antes de ser director de la Biblioteca Nacional de México (1879-1909), Vigil organizó la Biblioteca Pública del estado de Jalisco en 1861. 
"paz y del desarrollo de los elementos benéficos" de la nación, serían "el sentimiento de odio al sistema colonial" y el "desprecio hacia las razas vencidas” por los espańoles (Vigil 1992: 268).

La concepción de Vigil de la historia y el pasado concuerdan con una transformación en la forma de relacionarse con éste, en donde la integración de lo prehispánico y lo colonial permite establecer una salida a los problemas actuales así como sentar las bases de un itinerario hacia el progreso. La finalidad de la historia, bajo esta perspectiva, estaría encaminada a educar a la sociedad mexicana con vistas a su realización plena, que sería la tarea de los mexicanos del presente (que en este caso sería el de 1870). En este sentido, la historia tendría una doble tarea, como lo señala Guillermo Zermeño al describir las implicaciones que el Diccionario Universal de Historia y Geografia (1853-1856) tuvo en esta nueva concepción historiográfica: "proporcionar una nueva ilustración sobre el pasado" y "servir de ilustración pedagógica a los presentes" (158). Esta concepción, en la cual empezaría a considerarse a la historia una disciplina científica que permite, a partir de una serie de procedimientos metodológicos, ilustrar a los ciudadanos de un presente conflictivo e imperfecto, aparece claramente en el texto de Vigil:

Si supiésemos con toda certeza los antecedentes históricos de las razas que pueblan nuestro territorio; las encontradas corrientes de ideas que sobre ella han influido; sus relaciones con el suelo que ocupan; las condiciones físicas y climáticas de éste; si supiésemos discernir con la precisión científica, que sólo puede ser el fruto de largos estudios, los elementos de bien y mal que nos ofrecen en confusa mezcla, para distinguir hasta dónde llegan las necesidades legítimas y hasta dónde comienzan las aspiraciones absurdas, estamos persuadidos que cesaría por encanto ese misterio que hoy nos abruma, y que haciendo lugar a esperanzas bien fundadas, podría emprenderse la obra fructuosa de nuestra regeneración, con la confianza del que sabe el fin a que se dirige (1992: 269).

Así, la historia, a la vez ejemplar e ilustrativa, es un elemento aglutinador de la identidad del pueblo mexicano pues conforma la narración unificadora necesaria para fusionar, en una identidad única, a la sociedad mexicana. Por ello, para Vigil, la enseñanza de la historia convertiría "a los habitantes de este país en hombres y ciudadanos [...] porque sólo así podrán amarlo, explotarlo e interesarse en su conservación [...] 
pues tal conocimiento no sólo nos hará apreciar los bienes inestimables que poseemos, sino que robustecerá la fe para marchar hacia el porvenir" (270). Asimismo, en esta postura teleológica con vistas a la construcción de una sociedad mejor, Vigil organiza la temporalidad en una línea evolutiva donde el pasado deficiente de la época colonial es integrado como el origen, el germen de la sociedad mexicana, cuyo conocimiento resulta imprescindible para resolver los problemas del presente: "Un sentimiento de odio al sistema colonial nos hizo envolver en un común anatema todo lo que procedía de aquella época, sin reflexionar que sean cuales fueren las ideas que sobre ello se tengan, allí están los gérmenes de nuestras costumbres y nuestros hábitos, y que su estudio, en consecuencia, es indispensable para el que quiere comprender los problemas de actualidad" (268).

Vigil no elabora la historia de México defendida en su artículo - tarea efectuada en esta misma década por Vicente Riva Palacio y cuyo resultado fue la obra colectiva de México a través de los siglos de la cual nuestro autor redactaría el tomo V, intitulado "La Reforma (18551867)" - 5 pero, en cambio, desarrolla una historia de la literatura nacional, publicada de modo incompleto en 1909, el mismo año de su muerte. $^{6}$

Los primeros escritos de Vigil sobre literatura mexicana datan de la década de 1870, con la publicación de dos ensayos, "Algunas observaciones sobre la literatura nacional" $(1872)^{7}$ y "Algunas consideraciones

${ }^{5}$ Este quinto volumen se publica en 1889 y es el último del proyecto. Los otros cuatro tomos son: I: "Historia antigua y de la conquista" (desde la antigüedad hasta 1521) por Alfredo Chavero; II: "Historia del virreinato" (1521-1807) por Vicente Riva Palacio; III: "La guerra de independencia" (1808-1821) por Julio Zárate y IV: "México independiente" (1821-1855) por Juan de Dios Arias y Enrique de Olavarría y Ferrari.

${ }^{6}$ Esta obra se publicó inconclusa, meses antes de morir su autor, sin portada, sin prólogo y sin pie de imprenta. Los ejemplares que de ella se encuentran en la biblioteca del Instituto de Investigaciones Filológicas de la unam y en la Biblioteca Nacional tienen estas características, lo que refuerza el carácter inconcluso de la obra. Adalberto Sánchez Navarro (1972) publicó una recopilación de los estudios sobre literatura elaborados por Vigil, bajo el título Estudios sobre literatura mexicana, donde integra, entre otros documentos, el proyecto inconcluso de esta historia.

${ }^{7}$ Artículo publicado originalmente en El Eco de Ambos Mundos, México, D. F., 12 de marzo de 1872. Para este trabajo, citaré la versión recogida por Ruedas de la Serna (1996). 
sobre literatura mexicana" $(1876),{ }^{8}$ en los cuales pone en perspectiva las tesis de Francisco Pimentel e Ignacio Altamirano sobre los inicios de la literatura nacional. Para el primero, ésta sería una continuación de la literatura colonial española, mientras que para el segundo, la verdadera literatura nacional nacería con la independencia. Vigil concuerda con Altamirano: una literatura nacional no puede basarse únicamente en la imaginación, ya que necesita un punto de partida: la historia propia, además de una realización temática y formal concreta: la de expresar el espiritu del pueblo mexicano. Es por esta razón que en el caso concreto de México, la literatura verdaderamente nacional sólo podía existir a partir de la independencia. Con la conquista española se produjo una transformación completa que implicó la implantación de una nueva lengua, una nueva religión y nuevas costumbres. De esta forma, durante trescientos años, México formó parte de la corona española, la cual gobernó en todos los aspectos de la sociedad. Por ello, el desarrollo de las letras durante este periodo fue "absolutamente análogo al que se seguía en la metrópoli, sufriendo de la misma decadencia que la pérdida de libertades políticas y religiosas había hecho sentir en la literatura” (Vigil 1996a: 266). La censura practicada en estas tierras (a través, entre otras medidas, del "poder misterioso de la Inquisición"), ejercía un control sobre todos los aspectos sociales y por lo tanto impidió que los poetas pudieran manifestar en su poesía los rasgos de su tierra que, como se mencionó anteriormente, forma parte de las características de una literatura verdaderamente propia.

Vigil continúa esta reflexión sobre la literatura nacional en "Algunas consideraciones sobre literatura mexicana", publicado cuatro años después, donde puede verse una clara consciencia historiadora, que propone ver el pasado nacional a partir de sus tres periodos: uno antiguo, uno medio y uno moderno, que corresponderían a: "las grandes épocas contenidas en los tiempos anteriores a la Conquista, [al] periodo de dominación española y [al] que parte de 1810 hasta nuestros días" (Vigil 1996b: 274). El escritor jalisciense realiza una defensa de la importancia de estudiar cada uno de estos periodos, con el fin de conocer el modo de ser, las costumbres, tanto de los "antiguos pobladores del Nuevo Mundo", como del periodo colonial, del cual señala el interés

${ }^{8}$ Publicado por partes en El Federalista, México, D. F., 21, 23 y 28 de septiembre; 5, 7, 12, 14 y 24 de octubre de 1876 . 
para el "pensador" y el poeta, pues su estudio llevaría a "examinar los orígenes y desarrollo de nuestra sociedad actual" (274).

Con respecto de la importancia del periodo colonial, hay dos ideas en sus reflexiones que quisiera rescatar: la primera es su consideración de esta época como el origen de la sociedad mexicana, pues es en esta etapa cuando se produce la "creación de una nueva sociedad", cuyo desarrollo "presenta un material inagotable al escritor de genio que rinde culto a la verdad filosófica y a la belleza poética" (274). La segunda radica en que esta nueva sociedad se describe a través de la idea de un mestizaje producto de "la diversidad de razas que desde aquellos tiempos poblaron el nuevo continente"; de un sincretismo que puso de manifiesto "las extrañas influencias a que no pudo sustraerse la idea cristiana al engastarse en las informes y misteriosas teogonías indígenas, la rara mezcla que resultó de las tradiciones americanas con el misticismo monacal" y, finalmente, del surgimiento de un nuevo lenguaje que se "revela en las profundas alteraciones que sufrió el idioma de los dominadores" (274). Serán estos tres elementos los que irán forjando la identidad nacional, que se da a partir de la "historia moderna" del México independiente. Sin estos "orígenes" no se podría entender la sociedad actual, señala Vigil (y por lo tanto tampoco sus problemas). Por eso, este periodo resulta tema fundamental para el escritor, y por eso también debía considerarse para la escritura de la literatura nacional.

La importancia de integrar los pasados anteriores a la independencia en una historia literaria será un proyecto (inconcluso) que Vigil realiza en su Historia de la literatura, obra que se publica en 1909. No se sabe a ciencia cierta cuándo inició su escritura, pero es muy probable, como lo indica Lilia Granillo Vázquez, que lo hiciera poco después de 1880, una vez que fue nombrado director de la Biblioteca Nacional (223). Es, en efecto, durante esta década que podemos situar los primeros trabajos más sistemáticos de Vigil sobre historia literaria mexicana. El primero es de 1891, con motivo de la celebración del descubrimiento de América. Para conmemorar este evento se le encomienda redactar la introducción de una antología de poetas hispanoamericanos que editará la Real Academia Española:

En el marco de las celebraciones del IV Centenario del descubrimiento de América, la Real Academia Española proyectó publicar una antología de poetas hispano-americanos. Al efecto, invitó a sus correspondien- 
tes del Nuevo Mundo a que le enviasen colecciones de las poesías más notables, de autores muertos y vivos, y una reseña histórica de la poesía cultivada en los respectivos países, desde la Conquista hasta el año 1892. La Academia Mexicana, apenas recibida la invitación, comisionó a tres de sus miembros para que realizaran dicho trabajo: Casimiro del Collado y José María Roa Bárcena se encargaron de la selección de autores y composiciones; José María Vigil escribió la 'Reseña histórica de la poesía mexicana’ que debía preceder el volumen (Díaz Alejo y Prado Velázquez: XVIII-XIX).

Ahora bien, esta "Reseña histórica" (publicada en 1891), según Francisco Monterde, fue la base para la posterior redacción de su Historia de la literatura mexicana:

La 'Reseńa histórica de la poesía mexicana', de Vigil, quedó concluida en diciembre de 1891: casi un ańo antes, por consiguiente, de la fecha en que iba a iniciarse la formación del tomo primero de la Antología de poetas hispano-americanos. El académico Vigil tuvo más tarde la intención de convertirla en una reseńa histórica de la literatura mexicana. Decidió ampliarla, incluyendo en ella la prosa; pero ese propósito no llegó a realizarse, pues su obra quedó inconclusa (Francisco Monterde, "Una antología conmemorativa. IV Centenario del descubrimiento", citado por Díaz Alejo y Prado Velázquez: XXI).

Las palabras de Monterde iluminan sobre la génesis de la Historia publicada en 1909, y también sobre el título con el que también se conoce esta publicación: Reseña histórica de la literatura mexicana.

Este libro interesa particularmente para ver cómo integra Vigil el pasado colonial, ya que está casi por entero dedicado a éste, pues, como indiqué anteriormente, la muerte le impidió concluir su proyecto. Así, su Historia consta de un solo volumen integrado por diez capítulos, el primero de los cuáles recoge lo poco que se conocía de la producción literaria prehispánica, donde se hace referencia a algunos himnos sagrados, elegíacos y 'filosóficos', así como a la producción de Nezahualcóyotl. Este capítulo, además del sexto dedicado al género dramático durante la época precolombina y el siglo XVI, son los únicos en donde aborda la producción 'literaria' de las culturas prehispánicas. Los otros capítulos se centran principalmente en el siglo XVI (del segundo al octavo) y, finalmente, los dos últimos abordan la primera mitad del xvir. El 
criterio de selección es amplio, no sólo incluye lo que se conoce como las bellas letras, sino también la producción científica y filosófica de la época. Siguiendo un modo tradicional de organización, sus capítulos, además del orden cronológico, se organizan en torno a los géneros literarios clásicos: la lírica, la épica y el drama. Sus principales fuentes son la Historia general de las cosas de la Nueva España de fray Bernardino de Sahagún para la época prehispánica y los estudios de Joaquín García Icazbalceta para la época de la colonia. Sin embargo, el libro recoge también un número considerable de textos inéditos que se encontraban en el acervo de la Biblioteca Nacional.

Si bien esta Historia amerita un análisis detallado, me detendré en algunas cuestiones que considero clave para entender el modo en cómo resuelve Vigil la integración del pasado colonial. En primer lugar, aparece ya una clara intención de situar a éste como los orígenes de lo que será la nación mexicana. Por tal motivo, se hace hincapié en el alto grado de desarrollo intelectual que, a pesar de las circunstancias históricas y de la censura ejercida por el poder eclesiástico y civil de la corona española, había en estas tierras. Así, por ejemplo, al escribir sobre la labor realizada por los miembros de las órdenes religiosas durante el siglo XVI indica lo siguiente:

Aprender las lenguas indígenas; establecer escuelas donde los neófitos adquiriesen los principios morales y sociales de la civilización cristiana; ensanchar la esfera de la instrucción hasta hacer accesibles los diversos ramos de la ciencia entonces constituida; establecer con la imprenta un poderoso agente intelectual, y trabajar en la producción de obras más apropiadas á las exigencias de aquella sociedad embrionaria; he aquí el programa sabiamente planteado y desarrollado con la ayuda eficaz del poder civil durante el siglo xvi. Así vemos que los trabajos que forman la brillante aurora de nuestra vida literaria, llevan el carácter distintivo de serenidad y de utilidad verdadera, como que tendían á la aplicación inmediata en el orden social, y á la investigación histórica de los diferentes pueblos que cubrían nuestro vasto territorio (Vigil 1909: 32; las cursivas son mías).

Siguiendo la misma idea de origen de la literatura nacional, Vigil resaltará los valores originales, aunque limitados, de las obras literarias de los autores de la época. Cabe mencionar que en su Historia, éste no hace distinción entre los autores nacidos en la metrópoli y aquellos 
oriundos del territorio americano, el criterio será entonces más formal y temático que biográfico: si bien todos pertenecen a la literatura española, es posible detectar en las producciones locales ciertos rasgos que los distinguirán de las letras producidas en la península. ${ }^{9}$ Por ejemplo, sobre los poetas que emigraban a América indica:

Entre tanto, aquellos heraldos de la belleza literaria [...] que traían como instrumentos el habla, las formas y los ideales artísticos de la nación conquistadora, no tardaban en sentirse subyugados por las suaves influencias del ambiente americano que abría a su inspiración nuevos horizontes, ofreciendo en sus composiciones poéticas bellos paisajes, adornados de flores y frutos de nuestro hermoso país, deslizándose en ellas palabras de la melodiosa lengua azteca y trazando animados cuadros de la sociedad naciente, de la nueva raza inteligente y apasionada, la cual ofrecia caracteres bien determinados que la diferenciaba de sus progenitores. De esta manera y bajo acción combinada de influencias recíprocas, medraba con vida propia la rama del lauro español transplantada aquende el océano (89; las cursivas son mías).

Además de un juicio crítico favorable a la Grandeza mexicana de Balbuena, el autor más trabajado y apreciado por Vigil será Juan Ruiz de Alarcón, a quien dedica un capítulo íntegro de su historia (el sexto). En cambio, cuando llega a establecer el juicio de la producción literaria del siglo xviI, en los dos últimos capítulos de su libro, no será tan elogioso. Su visión de este siglo nos interesa particularmente ya que ayudará a entender las opiniones que elaborará sobre sor Juana Inés de la Cruz en otros escritos. Así, siguiendo el rechazo al estilo gongorino que imperó, desde fines del siglo XVIII y durante todo el XIX, tanto en España como en México, Vigil escribe sobre uno de los rasgos distintivos de éste en el que se destaca

la preponderancia adquirida por la secta literaria llamada Gongorismo, que llegó a extenderse sobre todas las producciones intelectuales, tanto las sagradas como las profanas [...]. El mal procedía de la Metrópoli, donde veníase presentando de tiempo atrás como esfuerzo de erudición mal entendida para encarcelar al castellano en el modelo latino, no sólo

\footnotetext{
${ }^{9}$ En este sentido, por ejemplo, los autores abordados en el quinto capítulo de la historia (Gutierre de Cetina, Eugenio Salazar, Juan de la Cueva y Bernardo de Balbuena), nacieron en Espańa, pero son integrados como parte de la literatura colonial.
} 
con la introducción inmoderada de voces de esta lengua, sino lo que era de mayor trascendencia, con alteraciones sintácticas que daban a la frase un aspecto oscuro y ridículo (183-184).

Al igual de lo que sucederá con su lectura de la obra de sor Juana, Vigil atribuye estos 'vicios del lenguaje', en una visión moderna de la historia literaria, a la situación política y cultural de la época que, al coartar las libertades de los sujetos, impidió que éstos lograran creaciones espontáneas, originales y con estilo justo.

El escritor jalisciense no llegó en su Historia a los años en que sor Juana vivió y, por lo tanto, esta figura no es tratada en este libro. Sin embargo la monja novohispana será importante en sus consideraciones literarias. Tres son los textos en donde el intelectual jalisciense aborda la figura y la obra de sor Juana, que coinciden además con el periodo en el que se interesa por realizar un acercamiento historiográfico de la literatura nacional: un discurso pronunciado en su honor en el $\mathrm{Li}$ ceo Hidalgo y publicado posteriormente en forma de folleto titulado Composiciones leidas en la velada literaria que consagró el Liceo Hidalgo a la memoria de sor Juana Inés de la Cruz la noche del 12 de noviembre de 1874, aniversario del natalicio de la ilustre poetisa ${ }^{10} \mathrm{y}$ dos entradas, una en la "Reseña histórica de la poesía mexicana" (1891) y otra en la antología Poetisas mexicanas. Siglos XVI, XVII, XVIII y XIX (1893). ${ }^{11}$

En el discurso pronunciado en la velada literaria consagrada a la memoria de la monja el 12 de noviembre de 1874 en el Liceo Hidalgo, al hablar de la época en que ésta vivió, Vigil la describe como "un periodo de incubación de la sociedad actual" en la cual se "arrojaron todas las semillas cilivizatorias que han comenzado a desarrollarse y fructificar en nuestros días" (Vigil 1980: 475). Si bien se trató de un periodo oscuro, "como todos los de preparación", es posible reconocer en él: "el elemento enérgico de una autoridad omnímoda, [que] allegó, en derredor de sí, como un núcleo poderoso, todos esos elementos que estaban destinados a crear más tarde la nación mexicana" (475). Es entonces en su

\footnotetext{
${ }^{10}$ México, Imprenta del Porvenir, 1874. Este discurso se encuentra reproducido en Sor Juana Inés de la Cruz ante la historia. Biografias antiguas. La Fama de 1700. Noticias de 1667 a 1892. Recopilación de Francisco de la Maza. México: unam, 1980: 450475. Es de este documento del que tomaré las citas.

${ }^{11}$ Existe una edición facsimilar de este texto, editada por la UNAM en 1977 con estudio preliminar de Ana Elena Díaz Alejo y Ernesto Prado Velásquez.
} 
calidad de "precursora" que sor Juana es considerada con relación a la historia de la literatura nacional.

El discurso de Vigil inicia con la biografía de la monja, siguiendo el mismo camino emprendido por las notas biográficas escritas hasta entonces. En él se vuelve a destacar su ingenio e inteligencia visibles desde su infancia - basándose tanto en lo mencionado por sor Juana en la Respuesta a Sor Filotea como en lo que el Padre Calleja escribiera en su biografía. ${ }^{12}$ Sin embargo, hay ciertos rasgos que Vigil destacará de la vida de la monja que difieren de las visiones anteriores y que están encaminados a construir el valor ejemplar de ésta, quien logró sobresalir en una sociedad retrógrada y sin libertad. Su primer desacuerdo sale a relucir en el momento en que discute las explicaciones sobre la entrada de Juana Inés al convento elaboradas anteriormente, las cuales habían atribuido, bajo un influjo de las corrientes románticas, la decisión de la monja a un desencanto amoroso. Escribe Vigil al respecto:

Yo veo en sor Juana uno de esos espíritus superiores, muy fuertemente templados, y que son incapaces de sucumbir a debilidades vulgares. La varonil ambición de saber, la fiebre de la gloria llenaban por completo su inteligencia y su imaginación. Claro es que para aquella naturaleza excepcional, el matrimonio debía aparecer bajo un aspecto eminentemente prosaico y ridículo [...] debió aterrarla escogiendo en aquella dura alternativa el claustro, lo menos desproporcionado y más decente (453).

Sor Juana, cuyo genio era para Vigil indudablemente "antimonacal" - recordemos que estamos en pleno periodo posterior a las leyes de desamortización de los bienes eclesiásticos- tuvo que tomar una decisión "dictada por las exigencias de su sociedad", por ello, continúa Vigil, si hubiese nacido "en nuestro siglo y en un país como los Estados Unidos, en donde la mujer es suficientemente respetada para gozar de una posición independiente" (453), seguramente hubiera podido realizar el ideal de su vida, es decir, hubiera podido vivir sola. Como no fue el caso, optó por la solución que más le convenía: tomar los hábitos. Aquí cabe señalar un pequeño paréntesis a futuro: ésta será la interpre-

${ }^{12}$ Las dos principales fuentes sobre la vida de sor Juana durante el siglo xIx fueron la Respuesta a sor Filotea, escrita por la monja en 1691 y la Vida de sor Juana publicada por Diego Calleja en 1700. 
tación que Paz defenderá cien años después en su libro sobre la monja novohispana. ${ }^{13}$

Toda la semblanza que Vigil hace de la monja está dirigida a mostrar la capacidad intelectual y filosófica de ésta, su excepcionalidad y la injusticia de la época en la que le tocó vivir, y que no le permitió su pleno desarrollo. La Respuesta a Sor Filotea es para éste un "documento precioso" en el cual se puede conocer: "su privilegiada inteligencia, los sufrimientos de aquella alma inmensa, que en contradicción abierta con todo lo que la rodeaba, no podía ni siquiera darle vuelo a sus más legítimas e inocentes aspiraciones" (453). La exaltación de la figura de sor Juana se ve claramente en las palabras de admiración dirigidas por el intelectual jalisciense, la cual es considerada una figura excepcional, nacida en la época equivocada. Asimismo, éste señala constantemente cómo esa época de represión había sido felizmente superada en la era moderna de la nación mexicana. Por ejemplo, al referirse a la polémica desatada por la crítica que sor Juana realiza al sermón de Vieyra, señala: "En una época de libre discusión y de examen ilimitado como la nuestra, apenas puede comprenderse y valorizarse semejante gesto de audacia por parte de una mujer, que sólo contaba con las fuerzas de su inteligencia, en medio de una sociedad ignorante y fanática, en que dominaba sin contrapeso el sombrío poder de la Inquisición" (457).

En cuanto a los comentarios sobre sus poemas, podemos encontrar el mismo afán por destacar su valor intelectual y filosófico, hecho que se constata con la introducción de varios ejemplos a partir de los cuales Vigil concluye que la monja bien ameritó la fama que tuvo en su época:

Si se tiene en cuenta la situación que guardaba el país en la época que floreció, en que el despotismo de la dinastía austriaca en decadencia, hacía sentir su pernicioso influjo sobre todos los miembros de la vasta monarquía espańola, cayendo la literatura del puesto eminente a que un siglo antes la habían elevado Cervantes, Lope de Vega y Fray Luis de León, se comprende todo el valor de aquella inteligencia excepcional, que poseída de la ardiente pasión del saber, rompiendo las multiplicadas trabas que las preocupaciones sociales imponían a su sexo, se atreve a tocar cuestiones que en nuestro siglo aguardan todavía una solución, y

${ }^{13}$ Cfr. Octavio Paz, Sor Juana Inés de la Cruz o las trampas de la fe, México (1983), principalmente el segundo capítulo "Segunda Parte. Juana Ramírez (1648-1668)”. 
se expresa con una osadía que aún hay pocos ejemplos en las mujeres de nuestro tiempo (466).

Vigil invita de este modo a valorar las producciones de sor Juana, señalado que "son muy pocas las faltas de buen gusto que la decadencia habitual había introducido al estilo literario" (467). Está claro que bajo el "buen gusto" defendido por Vigil, el Sueño sale mal parado en su crítica — como en todas las críticas realizadas durante el siglo xix, y habría que decirlo, también en la apreciación de Amado Nervo- cuya poca calidad es atribuida a la imitación que puede verse en éste del poema de Góngora, y el cual, señala el crítico, difiere enormemente de sus otras composiciones.

Vigil reconoce entonces la importancia de la obra de sor Juana bajo un doble punto de vista: el de la forma literaria y el de la intención moral en ella contenida. En cuanto a la forma, le parece que sus obras están a la altura de "lo mejor que se ha escrito en literatura española", y en cuanto a la intención moral, encuentra en ella un modelo ejemplar en su lucha por la emancipación de la mujer. Es decir, nuestro autor establece una doble vía para aproximarse a la obra de la monja: por un lado, valora los aspectos formales de sus textos — siempre y cuando estén libres de la influencia gongorina- y, por otro, destaca la excepcionalidad de su personalidad, que la sitúan más allá de la historia y que hacen de la monja una figura ejemplar.

De este modo, la reconstrucción de la figura de sor Juana y la lectura que Vigil hizo de sus obras, permitió que ésta fuera integrada a una historia de la literatura nacional, en tanto parte de un pasado que permitía entender mejor al presente en miras de una marcha hacia el progreso. Asimismo, esta visión permitió integrar pasados "no ejemplares" como el prehispánico y el colonial. En este sentido, y como Alejandro Araujo lo señala, la recuperación y narración del pasado

se volvió estrategia para mostrar que el ritmo de la historia era también el desarrollo de la razón y de sus valores orientados a un fin de creciente progreso. La historia no rescató los valores atemporales para moralizar, aunque siguió siendo ejemplar. Fue usada para guardar la memoria de aquellos hombres que a través de sus actos habian hecho futuro, es decir, que habían dejado atrás un mundo injusto, inmoral, antiguo, para dar entrada a las nuevas condiciones modernas. Mirar la historia se volvió 
entonces posibilidad de reconocer las pruebas de un camino ascendente hacia el progreso (304; las cursivas son mías).

La construcción de sor Juana como figura excepcional, entra completamente dentro de este uso que de los personajes del pasado hizo la historia nacional decimonónica. Es por ello que, en general, encontramos una dicotomía entre la vida de la monja y sus poemas; estos últimos, vistos desde un punto de vista estético decimonónico, mostraban la desavenencia de haber sido producidos en una época desafortunada para las artes y las ciencias. Sin embargo, como pudimos ver en Vigil, el hecho de poder integrar esta producción dentro de un pasado superado permitió asimismo que los juicios hacia su obra fueran matizados. Ya no se trataba de un rechazo a toda su producción poética, como en el caso de las biografías y críticas que se hicieron de su obra a principios del siglo XIX, sino a una selección que procuraba establecer una diferencia entre sus poemas de influencia gongorina - siempre criticados- y otros poemas como las redondillas, los de tema amoroso y los Ovillejos que fueron considerados como portadores de una calidad artística innegable. ${ }^{14}$

Si bien en Vigil hay un intento por realizar una selección de la obra de la monja, es cierto también que muchos otros intelectuales y escritores no consideraron los poemas de sor Juana de este modo; los más claros ejemplos de esta postura son también los más conocidos: el rechazo de Altamirano y las críticas de Prieto o Zarco. La recuperación que realiza Vigil de la figura de sor Juana sirvió, por lo tanto, para establecer un puente con el pasado superado y mostrar la grandeza de una mujer nacida en "tierras mexicanas". Asimismo, generó la base de la recuperación posterior que de la monja novohispana hiciera el siglo xx, a cuyos críticos, biógrafos y comentaristas tocó la labor de armonizar su biografía y obra bajo el signo de una doble admiración, ya no sólo por su vida, sino también por la calidad de toda su producción poética.

\footnotetext{
${ }^{14}$ Por otro lado, será sor Juana Inés de la Cruz, junto con Josefina Pérez García Torres (1853-1894) quienes tendrán el mayor número de poemas recogidos en la antología Poetisas mexicanas. Siglos XVI, XVII, XVIII y XIX (ambas con 11 composiciones), que, como mencioné anteriormente, Vigil elaborara como encargo de Carmen Romero de Díaz para la una exposición internacional realizada en Chicago con motivo del cuarto centenario del descubrimiento de América, publicado en 1893.
} 
Las reflexiones de Vigil sobre sor Juana se relacionan con su propuesta de integrar la época colonial dentro de la historia de una literatura mexicana. Podemos identificar en ellas la importancia de articular una historia que tome en cuenta el pasado colonial para ver en él la fase embrionaria de lo que será el México independiente. Ambas son una etapa importante para comprender cómo fue forjándose la idea de una literatura nacional. Estudiar, rescatar y comprender cómo se fue generando este canon resulta una labor fundamental, que amerita un estudio más amplio y extenso, con el fin de recorrer la constitución de la disciplina en el siglo xIx y su desarrollo y afianzamiento en el xx.

\section{BibliografíA}

Araujo, Alejandro. Novela, historia y lecturas. Usos de la novela histórica del siglo XIX mexicano: una lectura historiográfica. México: Universidad Autónoma Metropolitana-Cuajimalpa / Universidad del Claustro de Sor Juana, 2009.

Caso, Antonio. "México, apuntamientos de cultura patria", en Obras completas, vol. IX. México: Universidad Nacional Autónoma de México, 1976.

Díaz Alejo, Ana Elena y Ernesto Prado Velázquez. "Introducción" y "José María Vigil", en Poetisas mexicanas. Siglos XVI, XVII, XVIII y XIX. Antología y prólogo de José María Vigil, ed. facsimilar [1ª ed. 1893]. Estudio preliminar de Ana Elena Díaz Alejo y Ernesto Prado Velázquez, México: Universidad Nacional Autónoma de México, 1977.

Estrella González, Alejandro. "La filosofía mexicana durante el régimen liberal: redes intelectuales y equilibrios políticos", en Signos filosóficos, 12 (23), 2010: 141-181. Consultado en línea < http://www.scielo.org.mx/ scielo.php?script=sci_arttext\&pid=S166513242010000100006\&lng=e s\&tlng=es> (16 de octubre de 2014).

Granillo VÁzquez, Lilia. "'Lo que más nos interesa': historiar la literatura mexicana según José Ma. Vigil", en Historiografía de la literatura mexicana. Ensayos y comentarios. Jorge Ruedas de la Serna (coord.), México: Universidad Nacional Autónoma de México, 1996: 213-233.

Hernández Prado, José. "Estudio introductorio" a José María Vigil. Textos filosóficos. México: Universidad Autónoma Metropolitana-Azcapotzalco, 2005.

Illades, Carlos. "Ciencia y metafísica en el siglo xix", en Carlos Illades y Georg Leidenberger (eds.). Polémicas intelectuales del México moder- 
no. México: Universidad Autónoma Metropolitana / Consejo Nacional para la Cultura y las Artes, 2008: 69-114.

Navarro Sánchez, Adalberto. “Introducción”, en José María Vigil. Estudios sobre literatura mexicana. Recopilación, introducción y notas de A.S.N. México: Et Caétera, 1972: IX-XXIII.

Sánchez Cuervo, Antolín. Krausismo en México. México: Universidad Nacional Autónoma de México / Jitanjáfora / Red Utopía, 2004.

Sor Juana Inés de la Cruz y las vicisitudes de la crítica. Edición de José Pascual Buxó. México: Universidad Nacional Autónoma de México, 1998.

Vigil, José María. Historia de la literatura mexicana. México: s.e., 1909.

VIGIL, José María. Estudios sobre literatura mexicana. Recopilación, introducción y notas de Adalberto Navarro Sánchez. México: Et Caétera, 1972.

Vigil, José María. "Sor Juana Inés de la Cruz", en Sor Juana Inés de la Cruz ante la historia. Biografías antiguas. La Fama de 1700. Noticias de 1667 a 1892. Recopilación de Francisco de la Maza. México: Universidad Nacional Autónoma de México, 1980.

VigiL, José María. "Necesidad y conveniencia de estudiar la historia patria", recopilado en Juan A. Ortega y Medina. Polémicas y ensayos mexicanos en torno a la historia. México: Universidad Nacional Autónoma de México, 1992.

VIGIL, José María. “Algunas observaciones sobre la literatura nacional”, en $\mathrm{La}$ misión del escritor. Ensayos mexicanos del siglo XIX. Organización y presentación de Jorge Ruedas de la Serna, México: Universidad Nacional Autónoma de México, 1996a: 261-271.

VIGIL, José María. “Algunas consideraciones sobre la literatura mexicana”, en La misión del escritor. Ensayos mexicanos del siglo XIX. Organización y presentación de Jorge Ruedas de la Serna, México: Universidad Nacional Autónoma de México, 1996b: 273-284.

Vigil, José María. Textos filosóficos. Edición y estudio introductorio de José Hernández Prado. México: Universidad Autónoma Metropolitana-Azcapotzalco, 2005.

Zermeño Padilla, Guillermo. La cultura moderna de la historia. Una aproximación teórica e historiográfica. México: El Colegio de México, 2002. 